\title{
ESI-Mass spectrometry as a tool for investigating the mechanistic role of a 15-membered triolefinic macrocyclic palladium(0) complex in the Heck reaction
}

\author{
Anna Pla-Quintana and Anna Roglans* \\ Department of Chemistry, Universitat de Girona, 17071-Girona, Spain \\ E-mail: anna.roglans@udg.es
Dedicated to Professors José Elguero (CSIC-Madrid) and Pedro Molina (University of Murcia) on the occasion of their $70^{\text {th }}$ and $60^{\text {th }}$ anniversaries
(received 19 Nov 04; accepted 18 Jan 05; published on the web 27 Jan 05)

\begin{abstract}
Analysis of organometallic reaction mixtures by ElectroSpray Ionization Mass Spectrometry (ESI-MS) has permitted direct observation of Heck reaction intermediates using a 15-membered triolefinic macrocyclic palladium(0) complex as a recoverable catalyst. Knowledge has been gained of the role of the above- mentioned palladium complex in the Heck reaction by using arenediazonium salts.
\end{abstract}

Keywords: ESI-mass spectrometry, Heck reaction, reaction mechanisms, palladium, olefinic macrocyclic complexes, catalysis

\section{Introduction}

In the last five years, Moreno-Mañas et al. and ourselves have discovered a new family of 15membered triolefinic macrocycles of type 1 (Figure 1) which have an excellent coordination ability for certain transition metals (compounds 2 in Figure 1). Versatile syntheses, structural characterization, and multiple applications of macrocycles $\mathbf{1}$ and complexes $\mathbf{2}$ have been reviewed in two recent publications. ${ }^{1}$ Among complexes of type $\mathbf{2}$, the palladium(0) complexes have shown excellent catalytic activity in certain organic reactions traditionally catalyzed by palladium species. ${ }^{1}$ One of the advantages of this kind of palladium macrocyclic complexes is the absence of phosphanes as ligands for palladium, permitting its recovery and reuse.

In 2003 we published on the high catalytic activity of one of these palladium(0) complexes of type $\mathbf{2}$ (specifically 2a) for the Heck reaction of arenediazonium salts with acrylates and styrene under mild reaction conditions (Scheme 1). ${ }^{2}$ The phosphane-free palladium(0) complex 2a was recovered quantitatively by column chromatography at the end of the reaction. 

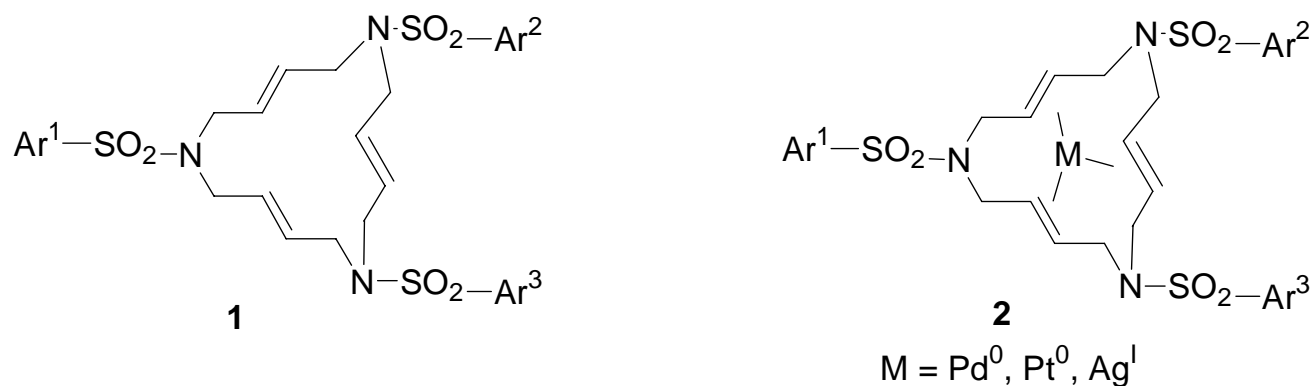

Figure 1. General structure of macrocycles $\mathbf{1}$ and their transition-metal complexes 2.

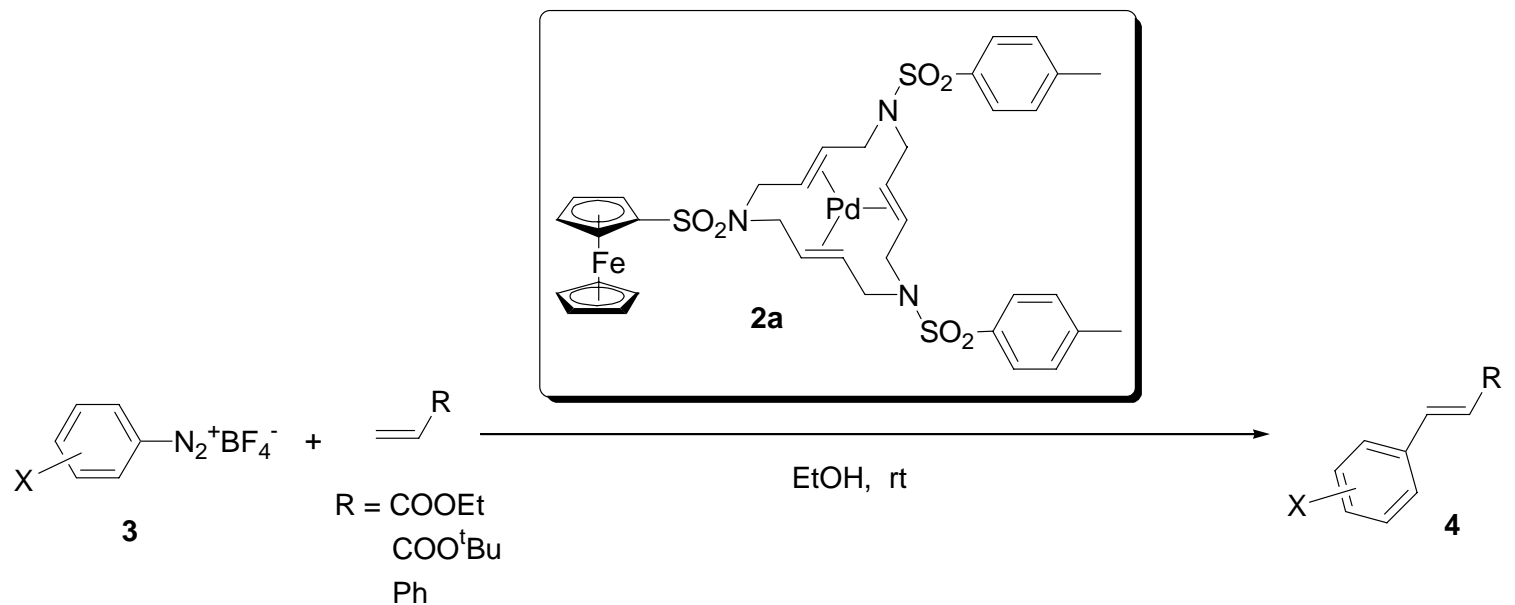

Scheme 1. Heck reaction of arenediazonium salts using palladium(0) complex $2 \mathbf{a}$.

One of the aspects which intrigued us was the role of these macrocyclic palladium complexes in the Heck mechanism. A plausible mechanistic hypothesis is that the Heck reaction takes place inside the macrocyclic system.

Electrospray ionization mass spectrometry (ESI-MS) ${ }^{3}$ is a soft ionization technique which has become increasingly popular as a mechanistic tool for studying short-lived reactive intermediates involved in organometallic catalytic reactions. ${ }^{4}$ The gentleness by which ions are formed in ESI-MS is an important feature for its application in organometallic chemistry. ${ }^{5}$ In addition, ESI-MS also permits working directly from dilute solutions. This is a major advantage in studies of catalytic species that exist only under these conditions. ESI-MS has been used recently for the screening of palladium catalysts ${ }^{6}$ and for the determination of the mechanism of the Heck reaction with arenediazonium salts. ${ }^{7}$

We now report the use of ESI-MS as an analytical tool to observe transient catalytic intermediates involved in the Heck reaction of arenediazonium salts using the olefinic macrocyclic palladium(0) complex 2a. The specific goal of this study was the direct detection by mass spectrometry of the intermediates within the reaction mixture in order to learn more about the catalytic role of the palladium(0) complex $2 \mathbf{a}$. 


\section{Results and Discussion}

We first checked the behavior of palladium(0) complex 2a by means of ESI-MS. Solutions of complex 2a were sprayed directly under routine ESI conditions. In ESI-MS only ionic compounds can be detected [cations in the ESI(+) mode and anions in the ESI(-) mode]. For samples which already contain ions, no further ionization is needed. However, neutral species need to be converted into a related ionic system for their detection. In some cases, electrochemical processes occurring in the charged probe tip promote the oxidation of electronrich compounds to generate $[\mathrm{M}]^{+}$ions. ${ }^{8}$ These oxidation processes are unpredictable and seem to be compound- and instrument- dependent. One of the most typical types of substrates that show this electrochemical behavior are metallocenes. ${ }^{9}$

The ability of the ferrocenyl unit in the palladium(0) complex 2a to suffer an oxidation process in the spectrometer was shown in its spectrum. As shown in Figure 2, the molecular ion $[\mathrm{M}]^{+}$at $\mathrm{m} / \mathrm{z}$ 866-875 (869) ${ }^{10}$ was detected, together with species generated from the association of 2a with other ions such as $\left[\mathrm{M}+\mathrm{NH}_{4}\right]^{+}$at $\mathrm{m} / \mathrm{z}$ 884-893 (887) and $[\mathrm{M}+\mathrm{Na}]^{+}$at $\mathrm{m} / \mathrm{z}$ 889--898 (892). Moreover, peaks due to species containing palladium were easily detected by the characteristic isotope distribution of the metal $\left[{ }^{102} \mathrm{Pd}(1.02 \%),{ }^{104} \mathrm{Pd}(11.14 \%),{ }^{105} \mathrm{Pd}(22.33 \%)\right.$, ${ }^{106} \mathrm{Pd}$ (27.33\%), ${ }^{108} \mathrm{Pd}$ (26.46\%) and $\left.{ }^{110} \mathrm{Pd}(11.72 \%)\right]$. Theoretical isotope patterns were calculated by use of the Isoform program and used to help the assignment (see the inset spectrum in Figure 2).

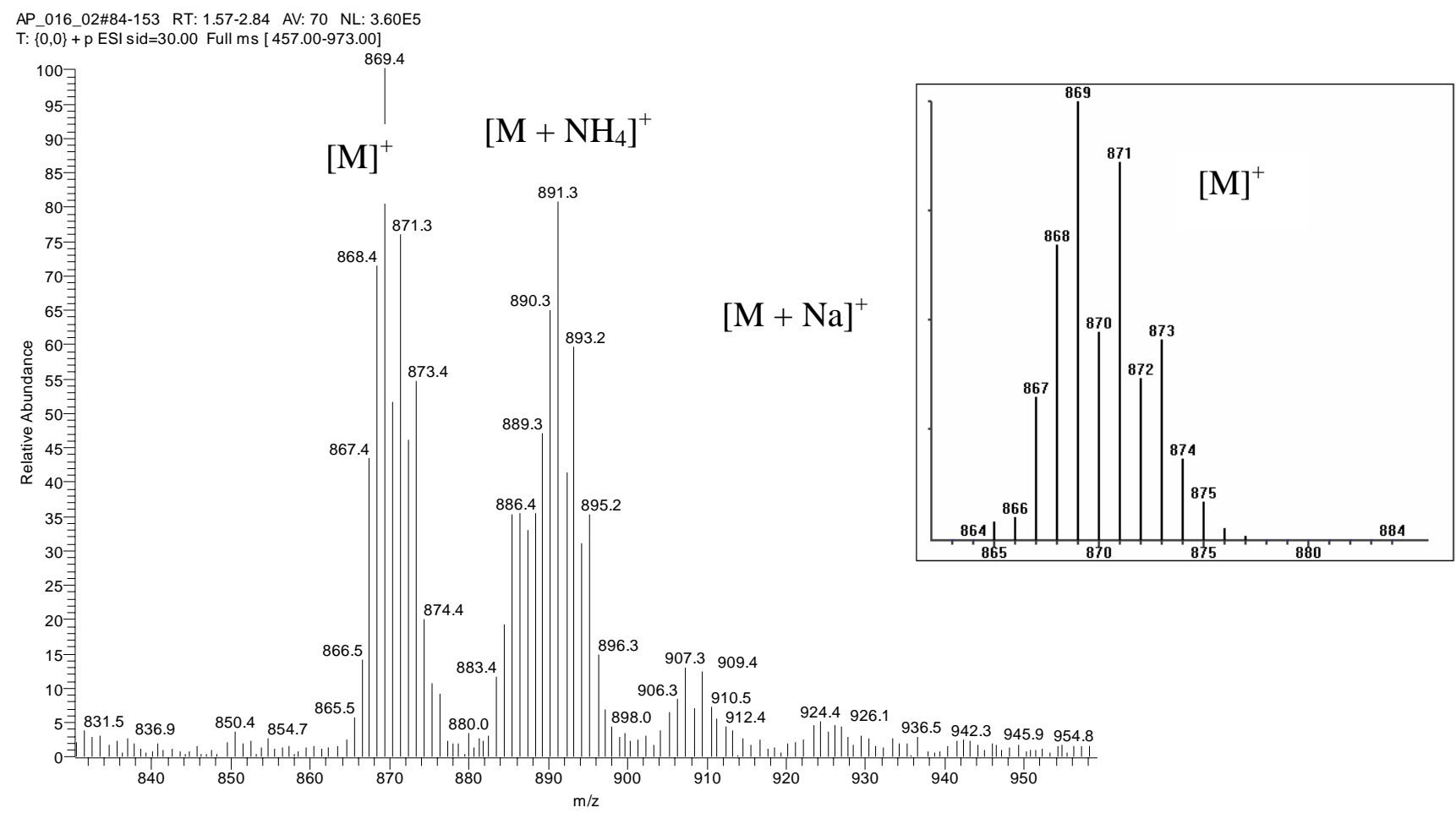

Figure 2. ESI(+)-MS spectrum of palladium(0) complex 2a in $\mathrm{MeOH} / \mathrm{H}_{2} \mathrm{O}$. The inset shows the theoretical isotope pattern for $[\mathrm{M}]^{+}$. 
The ESI mass spectrum was also recorded for benzenediazonium tetrafluoroborate $\mathbf{3 a}(\mathrm{X}=$ $\mathrm{H})$, and a peak at $\mathrm{m} / \mathrm{z} 105$ corresponding to $\left[3 \mathbf{a}-\mathrm{BF}_{4}\right]^{+}$was detected as the most abundant ion.

The catalytic cycle for the Heck reaction with arenediazonium salts represented in Scheme 2 was initially proposed by Kikukawa et al. ${ }^{11}$

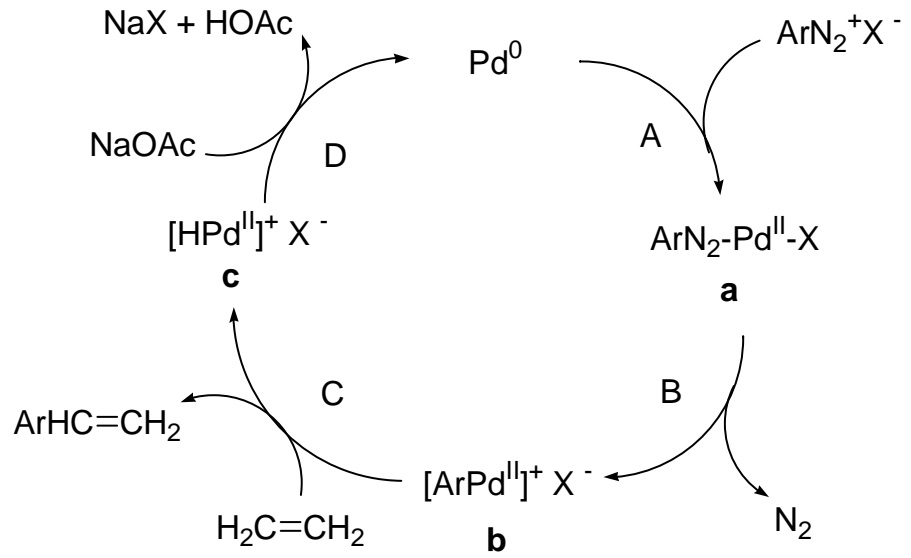

Scheme 2. Mechanistic cycle proposed by Kikukawa et al. for the Pd-catalyzed Heck reaction with arenediazonium salts.

A special feature of this proposed mechanism compared to the general Heck mechanism is that the formation of the Pd-C bond occurs in two steps (steps A and B). First, an arenediazonium-palladium complex a (step A) is formed which, in a second step, undergoes molecular nitrogen extrusion to give arylpalladium species $\mathbf{b}$ (step B). The cationic nature of the postulated species $\mathbf{b}$ prompted us to monitor the Heck reaction using palladium(0) complex 2a (Scheme 1) by means of ESI-MS. ${ }^{12}$

Our procedure consisted in mixing equimolar amounts of several arenediazonium tetrafluoroborates 3 with the palladium(0) complex 2a in methanol at room temperature until nitrogen gas bubbling was finished (see the Experimental Section for full details and for ESI-MS conditions). Samples of the reaction mixtures were then injected into the mass spectrometer for analysis. The results are summarized in Table 1.

The ESI-MS for mixtures of 2a and arenediazonium salts 3a-d (entries 1-4, Table 1) showed, in all four cases, a peak corresponding to the oxidative addition species $\mathbf{I}$ of type $\mathbf{b}$ (Scheme 2). In Figure 3a the spectrum corresponding to entry 1 in Table 1 is shown. In addition to the above-mentioned cluster, a peak at $\mathrm{m} / \mathrm{z} 763$ consistent with the free macrocyclic ligand derived from palladium loss in 2a was also observed. It is highly characteristic of the ESI-MS of coordination complexes that fragmentation typically causes loss of a complete ligand rather than fragmentation of the ligand. ${ }^{3,5}$ 
Table 1. Species detected in mixtures of arenediazonium salts 3 and $\operatorname{Pd}^{0}$ complex $2 \mathbf{2}$ by electrospray ionization mass spectrometry

\begin{tabular}{|c|c|c|c|}
\hline Entry & $\begin{array}{l}\text { Arenediazonium } \\
\text { tetrafluoroborate } 3\end{array}$ & $\mathrm{X}$ & Detected species $^{10}$ \\
\hline 1 & 3a & $\mathrm{H}$ & $\begin{array}{l}\mathrm{m} / \mathrm{z} 763[\mathbf{2 a}-\mathrm{Pd}]^{+} \\
\mathrm{m} / \mathrm{z} 840\left[\mathbf{2 a}-\mathrm{Pd}+\mathrm{C}_{6} \mathrm{H}_{5}\right]^{+} \\
\mathrm{m} / \mathrm{z} 868\left[\mathbf{2 a}-\mathrm{Pd}+\mathrm{C}_{6} \mathrm{H}_{5} \mathrm{~N}_{2}\right]^{+} \\
\mathrm{m} / \mathrm{z} 943-952(946) \mathbf{I a}\end{array}$ \\
\hline 2 & $\mathbf{3 b}$ & $p-\mathrm{NO}_{2}$ & $\begin{array}{l}m / z 763[2 \mathbf{a}-\mathrm{Pd}]^{+} \\
m / z \text { 988-997 (991) Ib }\end{array}$ \\
\hline 3 & $3 c$ & $p-\mathrm{CH}_{3}$ & $\begin{array}{l}m / z 763[2 \mathbf{a}-\mathrm{Pd}]^{+} \\
m / z \quad 854\left[2 \mathbf{a}-\mathrm{Pd}+p-\mathrm{CH}_{3} \mathrm{C}_{6} \mathrm{H}_{5}\right]^{+} \\
m / z \quad 882\left[2 \mathbf{a}-\mathrm{Pd}+p-\mathrm{CH}_{3} \mathrm{C}_{6} \mathrm{H}_{5} \mathrm{~N}_{2}\right]^{+} \\
m / z \text { 957-966 (960) Ic }\end{array}$ \\
\hline 4 & 3d & $p-\mathrm{F}$ & $\begin{array}{l}m / z 763[2 \mathbf{a}-\mathrm{Pd}]^{+} \\
m / z 961-970(964) \mathbf{I d}\end{array}$ \\
\hline 5 & $3 \mathbf{e}$ & $p-\mathrm{MeO}$ & $\begin{array}{l}\text { Several unidentified peaks without palladium } \\
\text { isotopic distribution }\end{array}$ \\
\hline
\end{tabular}

a) $30 \mathrm{eV}$

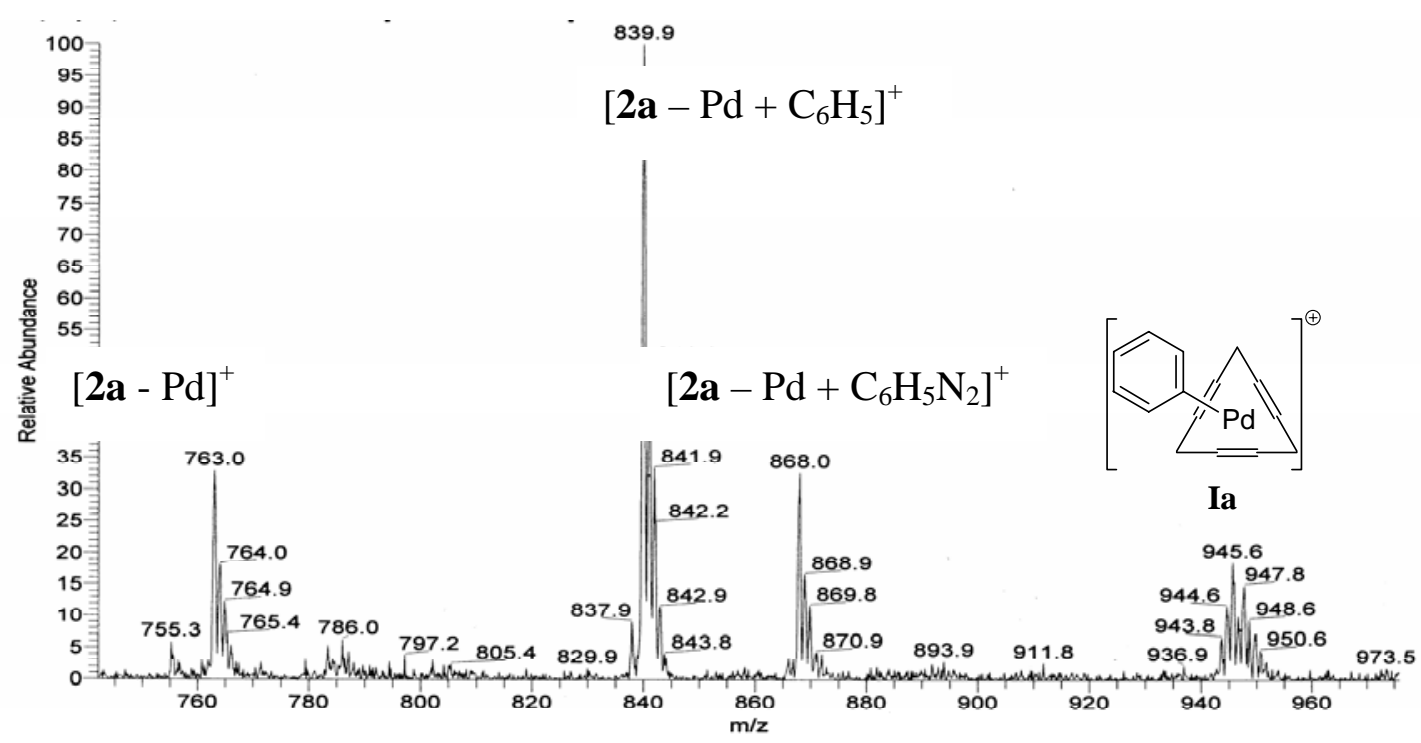


b) $80 \mathrm{eV}$

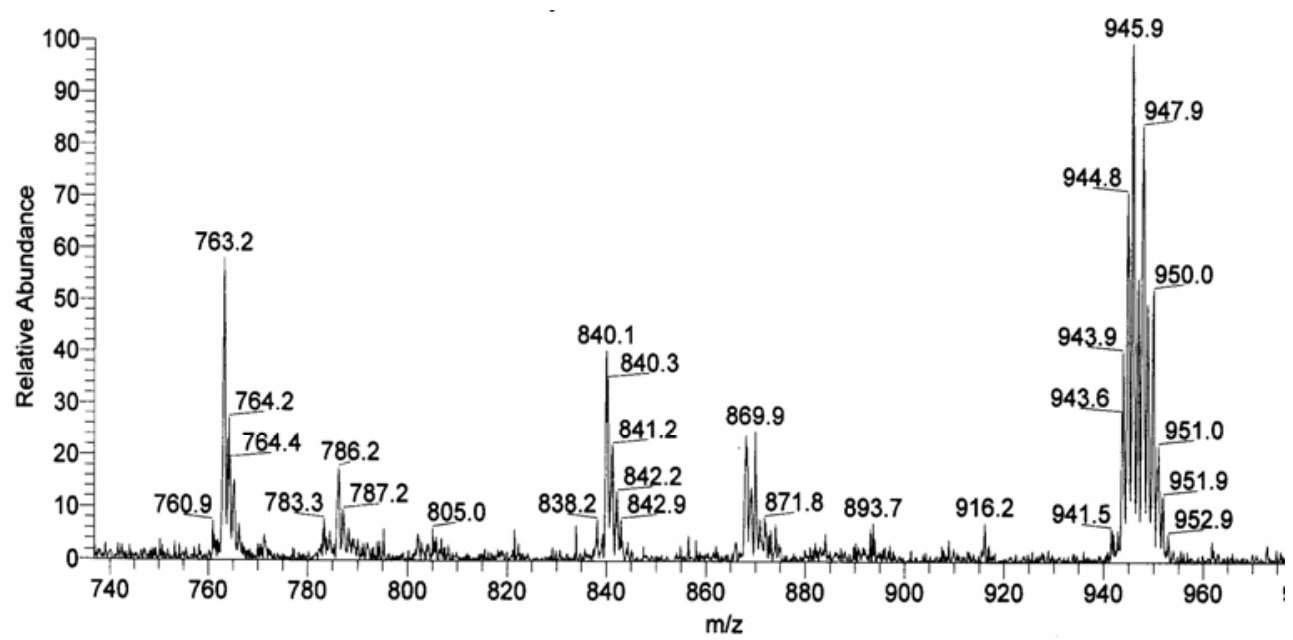

c) $100 \mathrm{eV}$

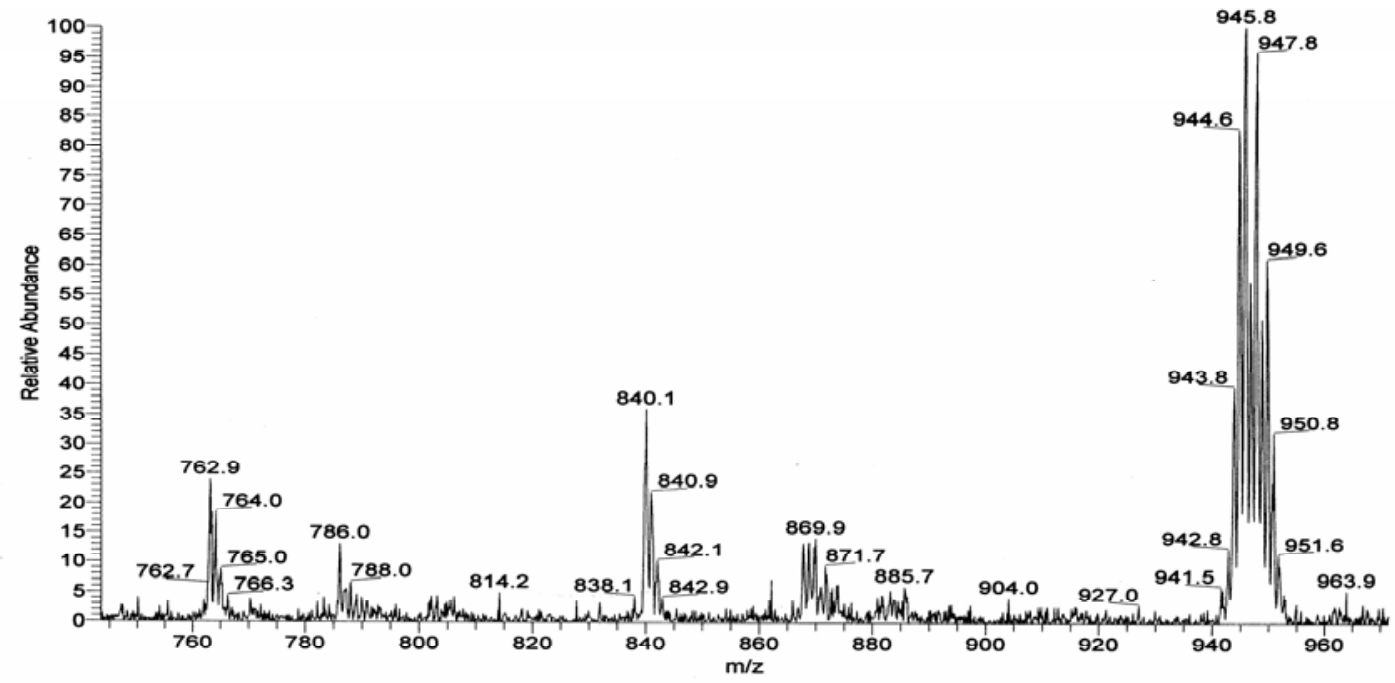

Figure 3. (a) ESI(+) mass spectra of an equimolar mixture of palladium(0) complex 2a and benzenediazonium tetrafluoroborate 3a. Effect of cone voltage on the ESI $(+)$ mass spectra for a mixture of 2a and 3a: (b) at $80 \mathrm{eV}$; (c) at $100 \mathrm{eV}$.

One of the aspects that worried us was the observation in the above ESI-MS spectra of peaks arising from association of the macrocyclic free ligand (2a - Pd) with arenediazonium derivatives (see peaks at m/z 840 and 868 in Figure 3). However, it is characteristic of the ESIMS technique that ionic adducts can be observed which are cone-voltage dependent and can be minimized by increasing the voltage. Therefore, in order to rule out that the cluster at $\mathrm{m} / \mathrm{z}$ 943953 (946) assigned to intermediate Ia could be an instrumental adduct, several injections were made at different increasing voltages. Effectively, the adduct peaks at $\mathrm{m} / \mathrm{z} 840$ and 868 diminish when the voltage was increased from $30 \mathrm{eV}$ to $100 \mathrm{eV}$. However, the cluster at $\mathrm{m} / \mathrm{z}$ 943-953 
(946) remained in the spectrum, demonstrating that it corresponds to the oxidative addition intermediate Ia (see spectra b and c in Figure 3). Other ESI-MS experiments were performed in order to confirm this experimental fact. An equimolar mixture of macrocyclic free ligand with benzenediazonium tetrafluoroborate $\mathbf{3 a}$ in methanol was injected into the spectrometer for analysis. The same instrumental adducts at $\mathrm{m} / \mathrm{z} 840$ and 868 were observed, and also disappeared when the cone voltage was increased.

For $p$-methylbenzenediazonium tetrafluoroborate, $3 \mathbf{c}$, the same kind of adducts were detected at $m / z 854$ and 882 showing analogous voltage-dependent behavior as for Entry 1 . Surprisingly, no ionic adducts were detected for the arenediazonium salts $\mathbf{3 b}$ and $\mathbf{3 d}$. This is an additional confirmation of the instrumental nature of these adducts.

In Figure 4, the intermediates I are represented for entries 2, 3, and 4 of Table 1.

a)

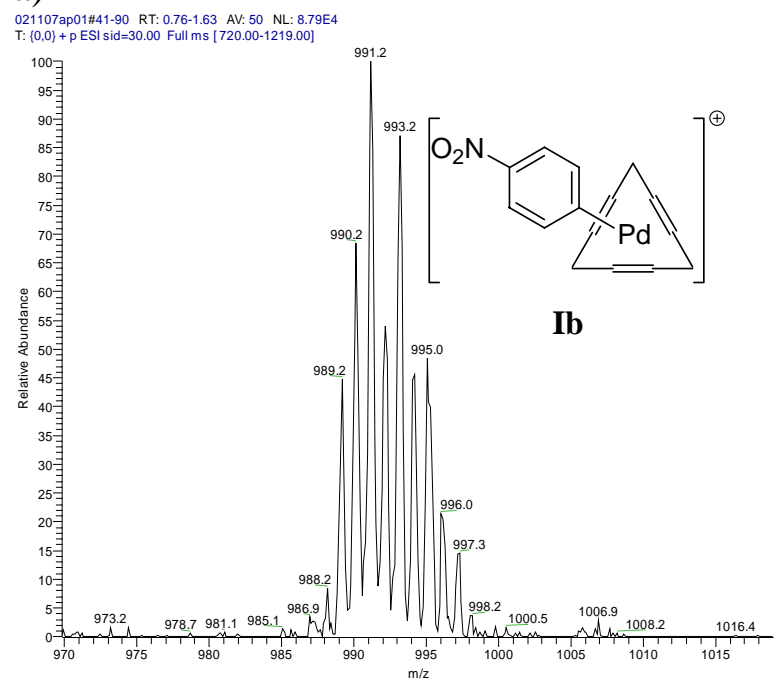

b)

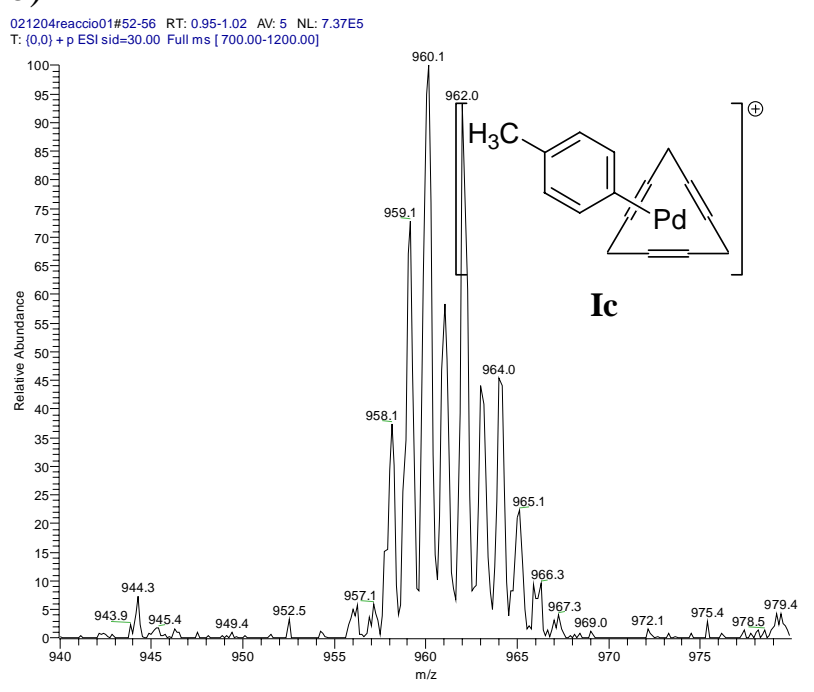

c)

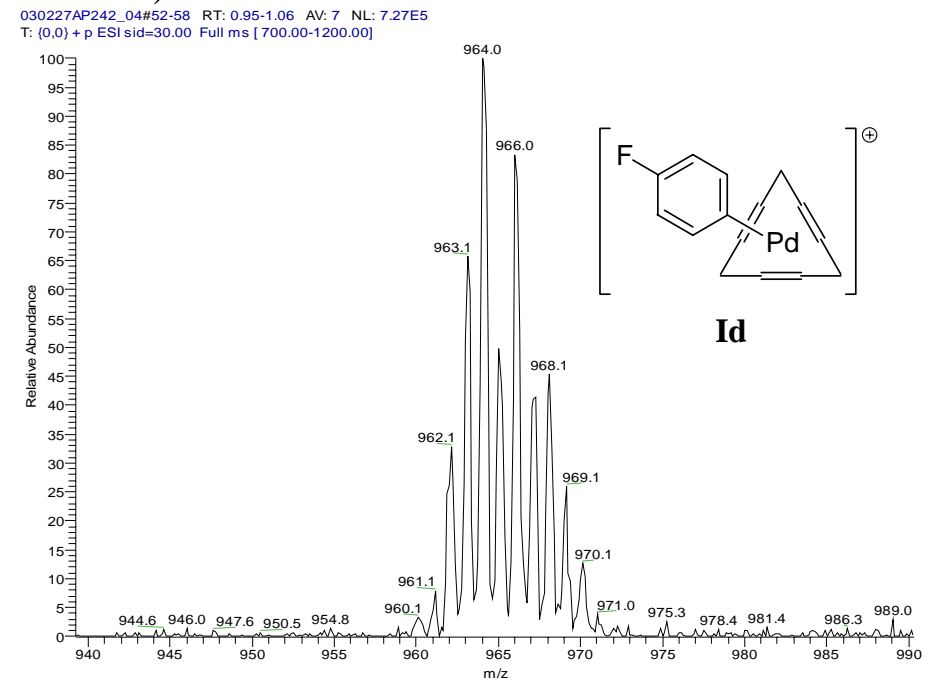

Figure 4. Experimentally observed clusters of intermediates Ib, Ic, and Id. 
In our last set of experiments, the olefinic compound (either ethyl acrylate or tert-butyl acrylate) was added to each of the previous solutions and the reaction mixtures were then monitored by ESI-MS. Samples were taken at 10-minute intervals until TLC indicated completion of reaction. Unfortunately, we did not observe any intermediate involving the olefin. ${ }^{13}$ However, when intermediates I started to disappear because the reaction went to completion, a peak corresponding to the palladium(0) complex 2a [m/z 866-875 (869)] started to emerge, demonstrating the recovery of catalyst $\mathbf{2 a}$ at the end of the reaction (see Figure 5 for the case of Ia).

a)

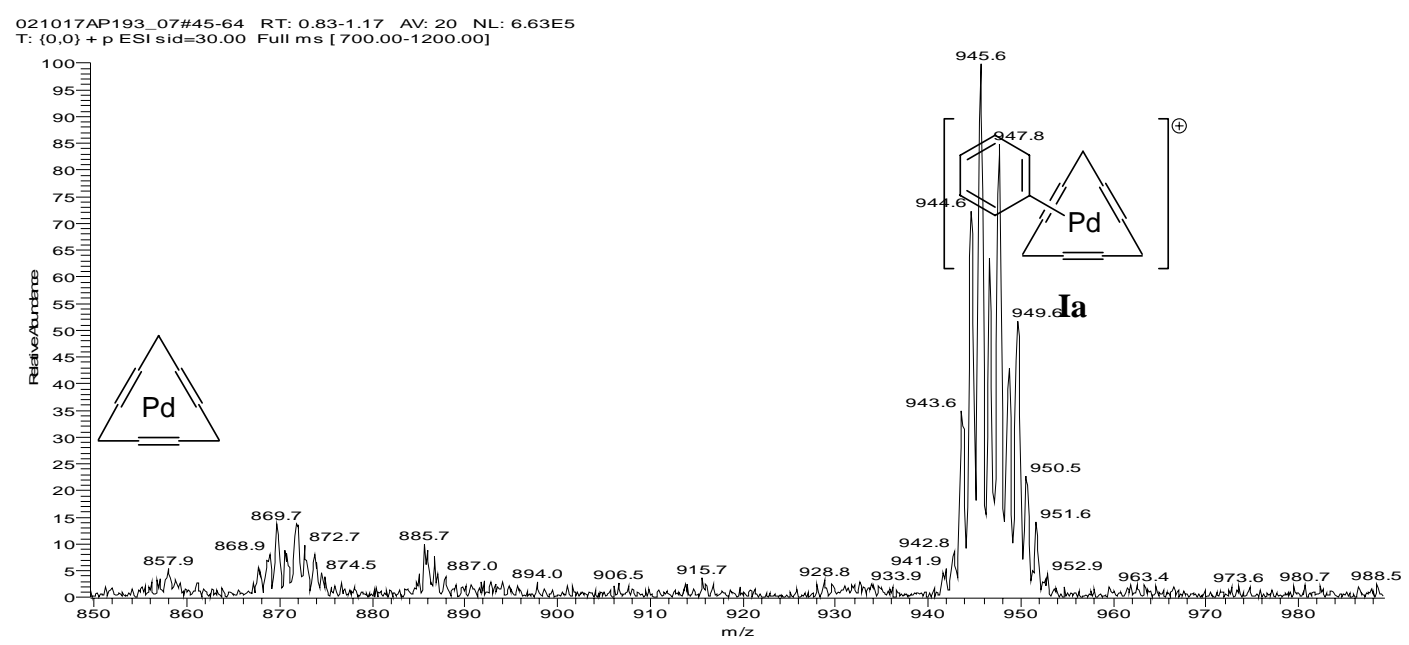

b)

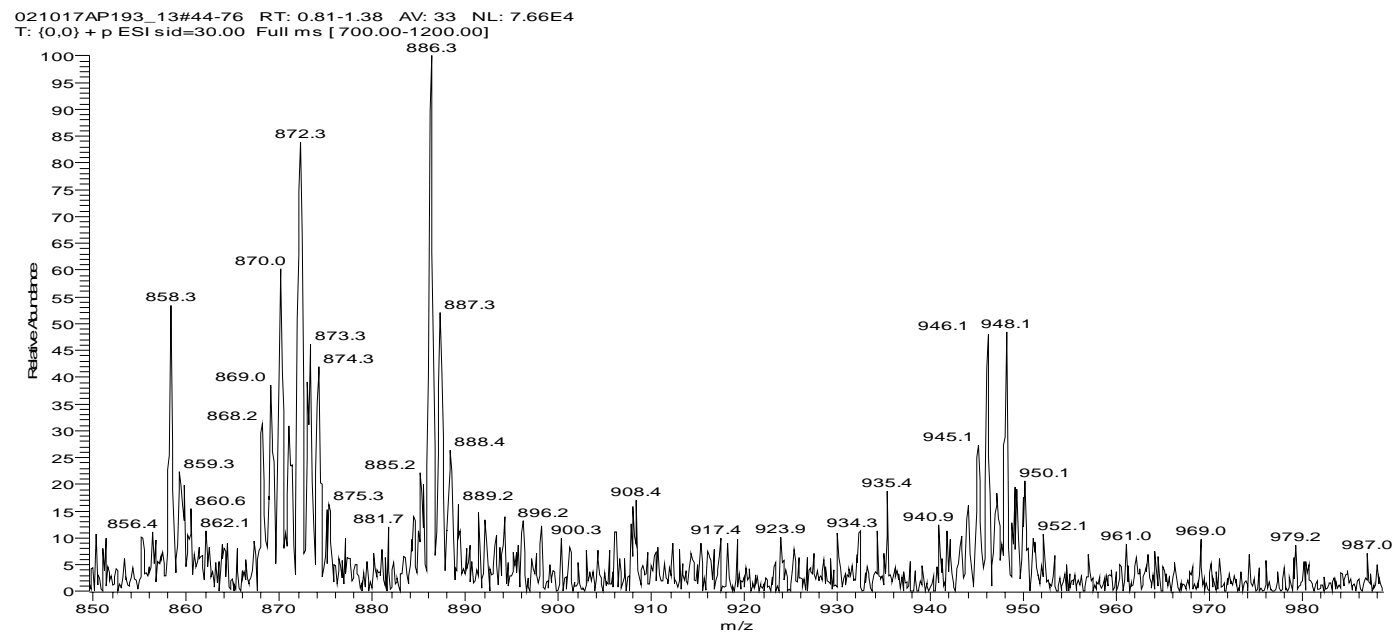


c)

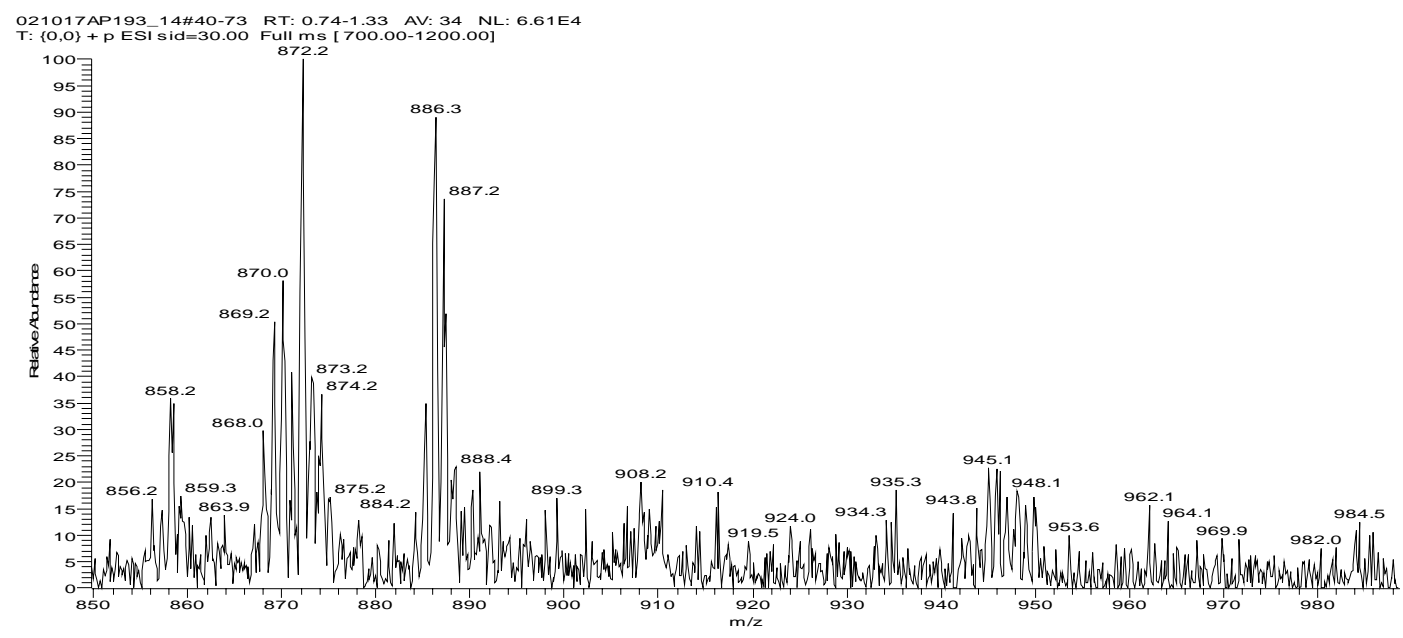

Figure 5. ESI(+)-MS of a mixture of 2a, 3a, and ethyl acrylate after mixing for: a) 10 minutes; b) 30 minutes; and c) 45 minutes.

Finally, analogous experiments were run under catalytic conditions (20\% molar of palladium(0) complex 2a) to afford data similar to the stoichiometric ones. Running the reaction with all the components [for example: 3a (1 equiv.) + olefin (1.5 equiv.) + 2a (0.2 equiv.)] gave no new data.

A proposed catalytic cycle showing the role of palladium(0) complex 2a in the Heck reaction with arenediazonium salts is shown in Scheme 3. On the basis of the ESI-MS results we can say that the first step in the catalytic cycle takes place inside the macrocyclic system. Since the palladium(0) complex 2a was recovered at the end of the reaction we can hypothesize that the whole reaction occurs in the macrocyclic system. In addition, since intermediate $\mathbf{I}$ is generated easily and is persistent in the ESI spectra until completion of the reaction, we can postulate that insertion of the olefin is the rate-determining step.

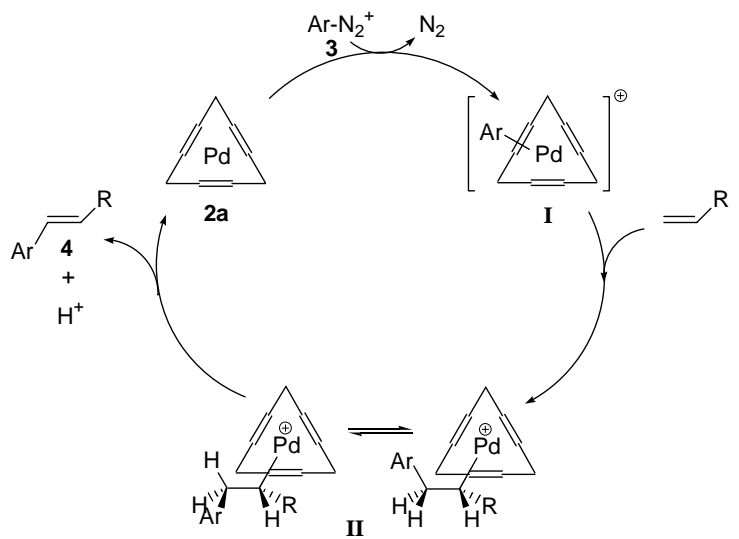

Scheme 3. Mechanistic role proposed for palladium(0) complex 2a in the Heck reaction with arenediazonium salts. 
Unfortunately, our ESI-MS study does not provide quantitative or detailed structural information about the observed intermediates. Attempts to isolate some intermediate in order to have suitable crystals for X-ray diffraction are underway.

\section{Experimental Section}

Solvents and reagents. Methanol, used to prepare reaction mixtures, was of HPLC grade and used without further purification. Arenediazonium tetrafluoroborates salts were prepared as described in the literature, ${ }^{14}$ and the palladium(0) complex 2a was synthesized by ourselves. ${ }^{2}$

Reaction mixture preparation. Reaction mixtures were prepared by combining the corresponding arenediazonium salt $3(0.012 \mathrm{mmol})$ and palladium(0) complex 2a $(0.012 \mathrm{mmol}$ for the stoichiometric version; $0.0024 \mathrm{mmol}$ (20\% molar) for the catalytic version) in $6 \mathrm{~mL}$ of methanol. Reaction mixtures were stirred at room temperature until the release of nitrogen gas was finished. Then, samples taken from reaction mixtures at various time intervals were diluted in methanol (solution of concentration ca $4 \mathrm{mM}$ ) and injected into the mass spectrometer for analysis. Finally, an excess of olefin (either ethyl acrylate or tert-butyl acrylate) (0.018 mmol) was added to the previous mixture and aliquots for injection were taken every 10 minutes until completion of the reaction.

Mass spectrometry. Electrospray mass spectrometry analyses were recorded on a Navigator quadrupole mass spectrometer (Finnigan AQA ThermoQuest) equipped with an electrospray ion source. The instrument was operated in the positive ESI $(+)$ ion mode at a probe tip voltage of $3 \mathrm{kV}$. The samples were introduced into the mass spectrometer ion source directly through a Rheodyne injector with a $20 \mu \mathrm{L}$ sample loop. The mobile-phase flow (100 $\mu \mathrm{L} / \mathrm{min}$ of 70:30 v/v $\mathrm{MeOH} / \mathrm{H}_{2} \mathrm{O}$ ) was delivered by a P2000 HPLC pump (ThermoQuest) to the vaporization nozzle of the electrospray ion source $\left(90^{\circ} \mathrm{C}\right.$ to $\left.165^{\circ} \mathrm{C}\right)$ and nitrogen was employed both as a drying- and nebulizing gas. Skimmer cone voltages were varied between 10 and $100 \mathrm{eV}$. Spectra were typically averages of 15-20 scans. Theoretical isotope patterns were calculated by use of the Isoform program and used to aid assignment.

\section{Acknowledgments}

We are indebted to Prof. M. Moreno-Mañas (Universitat Autònoma de Barcelona) for fruitful advice. Financial support from MCYT of Spain (Project No. BQU2002-04002-C02) and “Generalitat de Catalunya” (Project No. SGR2001-00291) are also gratefully acknowledged. 


\section{References}

1. (a) Moreno-Mañas, M.; Pleixats, R.; Roglans, A.; Sebastián, R.M.; Vallribera, A. ARKIVOC 2004, (iv), 109, (http://www.arkat-usa.org). (b) Moreno-Mañas, M.; Pleixats, R.; Sebastián, R.M.; Vallribera, A.; Roglans, A. J. Organomet. Chem. 2004, 689, 3669.

2. Masllorens, J.; Moreno-Mañas, M.; Pla-Quintana, A.; Roglans, A. Org. Lett. 2003, 5, 1559.

3. For a monograph on ESI-MS see: Cole, R.B. Electrospray Ionization Mass Spectrometry. Fundamentals, Instrumentation and Applications, Wiley: New York, 1997.

4. For uses of ESI-MS in direct observation of reaction intermediates see: (a) Wilson, S.R.; Pérez, J.; Pasternak, A. J. Am. Chem. Soc. 1993, 115, 1994. (b) Aliprantis, A.O.; Canary, J.W. J. Am. Chem. Soc. 1994, 116, 6985. (c) Arakawa, R.; Tachiyashiki, S.; Matsuo, T. Anal. Chem. 1995, 67, 4133. (d) Sam, J.W.; Tang, X.J.; Magliozzo, R.S.; Peisach, J. J. Am. Chem. Soc. 1995, 117, 1012. (e) Ripa, L.; Hallberg, A. J. Org. Chem. 1996, 61, 7147. (f) Brown, J.M.; Hii, K.K. Angew. Chem., Int. Ed. 1996, 35, 657. (g) Arakawa, R.; Matsuda, F.; Matsubayashi, G.E.; Matsuo, T. J. Am. Soc. Mass Spectrom. 1997, 8, 713. (h) Hii, K.K.; Claridge, T.D.W.; Brown, J.M. Angew. Chem., Int. Ed. 1997, 36, 984. (i) Feichtinger, D.; Plattner, D.A.; Chen, P. J. Am. Chem. Soc. 1998, 120, 7125. (j) Aramendía, M.A.; Lafont, F.; Moreno-Mañas, M.; Pleixats, R.; Roglans, A. J. Org. Chem. 1999, 64, 3592. (k) Volland, M.A.O.; Adlhart, C.; Kiener, C.A.; Chen, P.; Hofmann, P. Chem. Eur. J. 2001, 7, 4621. (1) Feichtinger, D.; Plattner, D.A. Chem. Eur. J. 2001, 7, 591. (m) Griep-Raming, J.; Meyer, S.; Bruhn, T.; Metzger, J.O. Angew. Chem., Int. Ed. 2002, 41, 2738. (n) Meyer, S.; Koch, R.; Metzger, J.O. Angew. Chem., Int. Ed. 2003, 42, 4700. (o) Chen, P. Angew. Chem., Int. Ed. 2003, 42, 2832. (p) Chevrin, C.; Le Bras, J.; Hénin, F.; Muzart, J.; Pla-Quintana, A.; Roglans, A.; Pleixats, R. Organometallics 2004, 23, 4796.

5. For the application of ESI-MS to inorganic and organometallic chemistry, see the following reviews and references cited therein: (a) Colton, R.; D’Agostino, A.; Traeger, J.C. Mass Spectrom. Rev. 1995, 14, 79. (b) Henderson, W.; Nicholson, B.K.; McCaffrey, L.J. Polyhedron 1998, 17, 4291. (c) Traeger, J.C. Int. J. Mass Spectrom. 2000, 200, 387. (d) Plattner, D.A. Int. J. Mass Spectrom. 2001, 207, 125. (e) Plattner, D.A. Top. Curr. Chem. 2003, 225, 153.

6. (a) Markert, C.; Pfaltz, A. Angew. Chem., Int. Ed. 2004, 43, 2498. (b) Tomazela, D.M.; Gozzo, F.C.; Ebeling, G.; Livotto, P.R.; Eberlin, M.N.; Dupont, J. Inorg. Chim. Acta 2004, 357, 2349.

7. Sabino, A.A.; Machado, A.H.L.; Correia, C.R.D.; Eberlin, M.N. Angew. Chem. Int. Ed. 2004, 43, 2514.

8. Van Berkel, G.J.; Zhou, F. Anal. Chem. 1995, 67, 3958.

9. (a) Xu, X.; Nolan, S.P.; Cole, R.B. Anal. Chem. 1994, 66, 119. (b) Van Berkel, G.J.; Quirke, J.M.E.; Tigani, R.A.; Dilley, A.S.; Covey, T.R. Anal. Chem. 1998, 70, 1544. (c) Henderson, W.; Olsen, G.M. Polyhedron 1998, 17, 577. 
10. For palladium-containing species, reported $\mathrm{m} / \mathrm{z}$ values are from the lowest to the highest mass in the isotope envelope of the cluster; the value in parentheses is the most abundant peak.

11. Kikukawa, K.; Nagira, K.; Wada, F.; Matsuda, T. Tetrahedron 1981, 37, 31.

12. Since palladium(0) complex 2a also catalyzes the Heck reaction of ethyl acrylate and iodobenzene and the Suzuki cross-coupling between iodobenzene and benzeneboronic acid [see reference (a) Llobet, A.; Masllorens, E.; Moreno-Mañas, M.; Pla-Quintana, A.; Rodríguez, M.; Roglans, A. Tetrahedron Lett. 2002, 43, 1425], we initially tried to detect by ESI-MS some intermediates in the above-mentioned reactions without any success. In all cases, only complex 2a was detected. Addition of $\mathrm{AgBF}_{4}$ to the reaction mixture in order to generate cationic species by displacement of iodine atom was also unsuccessful.

13. A full report on the ESI detection of intermediates of the Heck reaction using $\left[\left[\mathrm{Pd}_{2}(\mathrm{dba})_{3}\right]\right.$.dba, in which species involving the insertion of the olefin have been detected, has been published recently (see ref. 7) .

14. Roe, A. Org. React. 1949, 44, 1572. 